\title{
General circulation model assessment of direct radiative forcing by the sulfate-nitrate- ammonium-water inorganic aerosol system
}

\section{Citation}

Adams, Peter J., John H. Seinfeld, Dorothy Koch, Loretta Mickley, and Daniel Jacob. 2001. "General Circulation Model Assessment of Direct Radiative Forcing by the Sulfate-NitrateAmmonium-Water Inorganic Aerosol System." Journal of Geophysical Research 106, issue D1: 1097-1111.

\section{Published Version}

doi:10.1029/2000JD900512

\section{Permanent link}

http://nrs.harvard.edu/urn-3:HUL.InstRepos:14117801

\section{Terms of Use}

This article was downloaded from Harvard University's DASH repository, and is made available under the terms and conditions applicable to Other Posted Material, as set forth at http:// nrs.harvard.edu/urn-3:HUL.InstRepos:dash.current.terms-of-use\#LAA

\section{Share Your Story}

The Harvard community has made this article openly available.

Please share how this access benefits you. Submit a story.

Accessibility 


\title{
General circulation model assessment of direct radiative forcing by the sulfate-nitrate-ammonium-water inorganic aerosol system
}

\author{
Peter J. Adams and John H. Seinfeld \\ Department of Chemical Engineering, California Institute of Technology, Pasadena
}

Dorothy Koch

NASA Goddard Institute for Space Studies, New York

Loretta Mickley and Daniel Jacob

Division of Engineering and Applied Sciences, Harvard University, Cambridge, Massachusetts

\begin{abstract}
An on-line simulation of aerosol sulfate, nitrate, ammonium, and water in the Goddard Institute for Space Studies general circulation model (GCM II-prime) has been used to estimate direct aerosol radiative forcing for the years 1800,2000 , and 2100. This is the first direct forcing estimate based on the equilibrium water content of a changing $\mathrm{SO}_{4}{ }^{2-}-\mathrm{NO}_{3}{ }^{-}$$\mathrm{NH}_{4}{ }^{+}$mixture and the first estimate of nitrate forcing based on a global model of nitrate aerosol. Present-day global and annual average anthropogenic direct forcing is estimated to be -0.95 and $-0.19 \mathrm{~W} / \mathrm{m}^{2}$ for sulfate and nitrate, respectively. Simulations with a future emissions scenario indicate that nitrate forcing could increase to $-1.28 \mathrm{~W} / \mathrm{m}^{2}$ by 2100 , while sulfate forcing declines to $-0.85 \mathrm{~W} / \mathrm{m}^{2}$. This result shows that future estimates of aerosol forcing based solely on predicted sulfate concentrations may be misleading and that the potential for significant concentrations of ammonium nitrate needs to be considered in estimates of future climate change. Calculated direct aerosol forcing is highly sensitive to the model treatment of water uptake. By calculating the equilibrium water content of a $\mathrm{SO}_{4}{ }^{2-}-$ $\mathrm{NH}_{4}{ }^{+}$aerosol mixture and the optical properties of the wet aerosol, we estimate a forcing that is almost $35 \%$ greater than that derived from correcting a low relative humidity scattering coefficient with an empirical $f(\mathrm{RH})$ factor. The discrepancy stems from the failure of the empirical parameterization to adequately account for water uptake above about $90 \%$ relative humidity. These results suggest that water uptake above $90 \%$ RH may make a substantial contribution to average direct forcing, although subgrid-scale variability makes it difficult to represent humid areas in a GCM.
\end{abstract}

\section{Introduction}

The scattering and absorption of radiation by tropospheric aerosols, or direct forcing, has been identified as a key process in anthropogenic climate change [Intergovernmental Panel on Climate Change (IPCC), 1996]. Of all the chemical species present as atmospheric aerosol, sulfate is considered to be the largest contributor to anthropogenic direct forcing. Direct radiative forcing by sulfate aerosols has received considerable attention over the past decade; estimates of global mean forcing range between -0.29 and $-0.95 \mathrm{~W} / \mathrm{m}^{2}$ [Boucher and Anderson, 1995; Charlson et al., 1991; Chuang et al., 1997; Feichter et al., 1997; Haywood et al., 1997b; Kiehl and Briegleb, 1993; Kiehl et al., 2000; Koch et al., 1999; Penner et al., 1998; Taylor and Penner, 1994; Van Dorland et al., 1997].

Copyright 2001 by the American Geophysical Union.

Paper number 2000JD900512.

0148-0227/01/2000JD900512\$09.00
Despite the numerous studies devoted to the subject, the IPCC [1996] estimates that the magnitude of direct sulfate forcing remains uncertain by a factor of 2 . Disagreement over the atmospheric sulfate burden and the fraction of that burden that is caused by human activities accounts for some, but not all, of this uncertainty. Figure 1 shows various anthropogenic sulfate direct forcing estimates as a function of the corresponding anthropogenic sulfate burden. This plot makes it clear that even researchers assuming the same amount of anthropogenic sulfate may reach very different conclusions about the magnitude of the resulting forcing. The sulfate forcing efficiency, defined as the amount of forcing per mass of sulfate, implicit in these numbers, varies from -130 to -370 $\mathrm{W} / \mathrm{g} \mathrm{SO}_{4}{ }^{2-}$. Some of this variation reflects differences in the radiation models used to generate these estimates, but larger discrepancies result from other sources of uncertainty, including different assumptions regarding the optical properties of sulfate [Boucher et al., 1998]. The sensitivity of forcing estimates to aerosol optical properties has motivated several recent publications [Boucher and Anderson, 1995; Nemesure et al., 1995; Pilinis et al., 1995]. The range of 


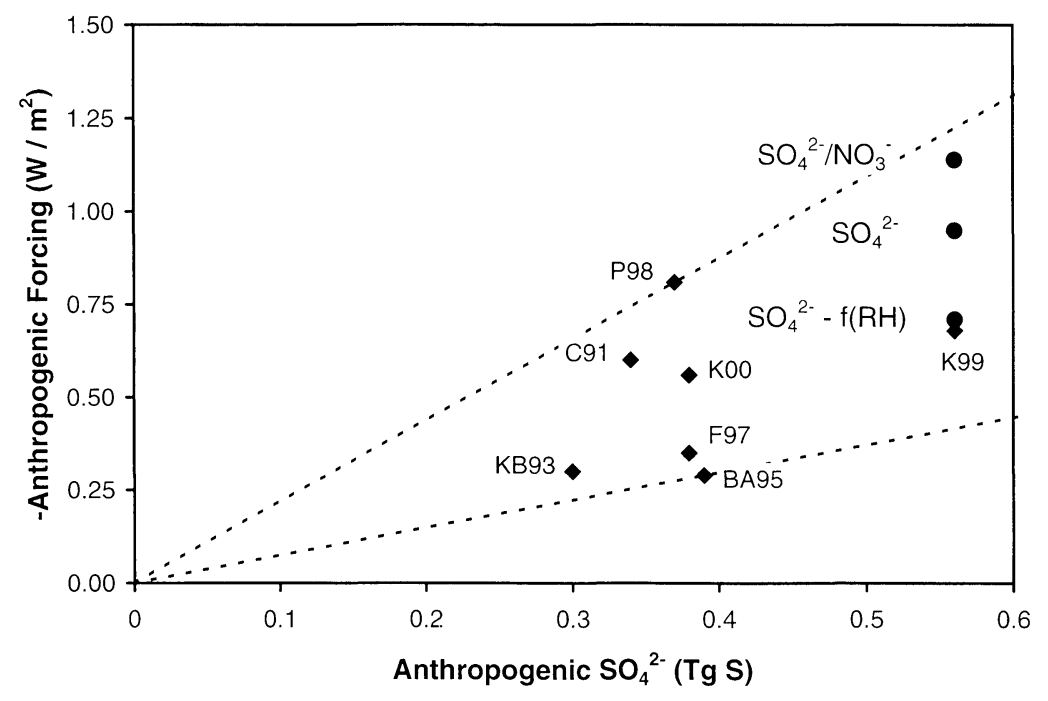

Figure 1. Estimates of anthropogenic sulfate direct forcing $\left(\mathrm{W} / \mathrm{m}^{2}\right)$ versus anthropogenic sulfate burden $(\mathrm{Tg}$ $\mathrm{S})$. Circles represent estimates from this work: $\mathrm{SO}_{4}{ }^{2-}$, sulfate forcing computed using composition dependent optical properties; $\mathrm{SO}_{4}{ }^{2-} / \mathrm{NO}_{3}{ }^{-}$, sulfate and nitrate forcing using same method; $\mathrm{SO}_{4}{ }^{2-}-f(\mathrm{RH})$, sulfate forcing computed using $\alpha \times f(\mathrm{RH})$ parameterization of aerosol optical properties. Diamonds represent other published estimates: BA95, Boucher and Anderson [1995]; C91, Charlson et al. [1991]; F97, Feichter et al. [1997]; KB93, Kiehl and Briegleb [1993]; K99, Koch et al. [1999]; K00, Kiehl et al. [2000]; P98, Penner et al. [1998]. Dashed lines represent the range of sulfate forcing efficiencies implicit in these estimates.

forcing efficiencies implicit in the literature is partly the result of a generation of aerosol models that predicted sulfate mass, but not sulfate optical properties per se. Narrowing the uncertainty in direct sulfate forcing requires, amongst other things, a more precise calculation of sulfate optical properties, especially the effect of water uptake. This, in turn, requires models that tell us more about the atmospheric aerosol than the mixing ratio of sulfate.

The size, shape, and refractive index of a particle uniquely determine its optical properties. Sulfate particles are generally hydrated, spherical droplets. Therefore given the size distribution, total mass (or number) of particles and refractive index, their optical properties may be calculated from a routine application of Mie scattering theory.

In addition to sulfate, accumulation mode aerosols contain significant amounts of nitrate in polluted areas. Both nitrate and sulfate are generally neutralized to a substantial degree by ammonia, which exists in the aerosol phase as the ammonium cation. Most importantly, inorganic aerosols are hygroscopic and contain water under nearly all atmospheric conditions. The amount of aerosol nitrate, ammonium, and water influence, with sulfate, the optical properties of the aerosol.

Of all these components, water plays perhaps the greatest role in determining aerosol optical behavior, simply because it constitutes most of the aerosol mass. Therefore the direct aerosol effect is similar to the indirect effect in the sense that shortwave radiation interacts with more water than sulfate. Investigating the sensitivity of direct forcing to a variety of parameters, Pilinis et al. [1995] found that it is most sensitive to changes in relative humidity and the corresponding water content of the aerosol. Moreover, water uptake is highly nonlinear. Ammonium sulfate particles, for example, triple in volume as relative humidity increases from $85 \%$ to $95 \%$, but grow by less than $20 \%$ (using the metastable hysteresis curve) from $50 \%$ to $60 \% \mathrm{RH}$. Water uptake also depends on the degree to which sulfate is neutralized by ammonia, with sulfuric acid being more hygroscopic than ammonium bisulfate or ammonium sulfate except near $100 \% \mathrm{RH}$. As a result, water uptake by inorganic aerosol is highly variable in time and space as relative humidity and aerosol composition change. Because it makes the dominant contribution to aerosol mass, water uptake influences the aerosol size distribution as particles grow and shrink with changing relative humidity. Particle size, in turn, influences its optical behavior. Water uptake also influences the refractive index of the aerosol mixture since its refractive index is lower than those of other aerosol species. For all these reasons, an accurate representation of aerosol forcing demands a realistic model of water uptake, including spatial and temporal variation resulting from changes in relative humidity and aerosol chemical composition.

Nitrate and ammonium each have a role in determining the optical properties of the aerosol mixture as well. As such, nitrate and ammonium contribute a small amount of mass to the inorganic aerosol, together only $7 \%$ of the total [Adams et al., 1999]. More importantly, each influences water uptake. Ammonium nitrate is hygroscopic such that it and accompanying water make a significant contribution to total aerosol mass and aerosol light scattering in industrialized areas. A previous global modeling study [Adams et al., 1999] concluded that ammonium nitrate is responsible for more aerosol mass than sulfate in much of Europe. The contribution of ammonium nitrate in North America and eastern Asia was predicted to be less, but still significant. Aerosol and light scattering measurements made by ten Brink et al. [1996, 1997] on the coast of the Netherlands show that ammonium nitrate scatters more sunlight than sulfate in this area. An analysis of observed aerosol concentrations in the eastern United States also shows that nitrate plays a key role in determining total aerosol mass, especially during winter 
[West et al., 1999]. Ammonia can be absorbed by sulfate particles and thereby modify their optical properties. Ammonium bisulfate and ammonium sulfate are both less hygroscopic than sulfuric acid at low to moderate relative humidities but have higher refractive indices. The net result of these two competing factors is that one mole of sulfuric acid scatters about $25 \%$ more sunlight than one mole of ammonium bisulfate at $80 \%$ relative humidity. Ammonium sulfate is intermediate between the two [Boucher and Anderson, 1995].

Previous estimates of direct radiative forcing undertaken with models that compute only the sulfate concentration have addressed the presence of nitrate, ammonium, and water in various ways. Van Dorland et al. [1997] roughly estimated the radiative forcing due to nitrate by assuming an arbitrary fraction of nitric acid exists in the aerosol phase with the same optical properties as sulfate. Otherwise, no global estimate of nitrate forcing exists. Dentener and Crutzen [1994] and Adams et al. [1999] have simulated the ammonia cycle and concentrations of aerosol ammonium without considering radiative effects. Radiative forcing assessments for sulfate have accounted for ammonium by assuming sulfate exists uniformly as $\left(\mathrm{NH}_{4}\right)_{2} \mathrm{SO}_{4}$ or, in some studies, $\mathrm{H}_{2} \mathrm{SO}_{4}$. Changes in water uptake and refractive index as a result of varying amounts of aerosol ammonium have therefore been neglected in previous work.

Previous work has accounted for the effect of water uptake on aerosol optical properties in various ways. In some studies [Charlson et al., 1991; Feichter et al., 1997], variations in relative humidity are ignored, and a single value of the aerosol scattering cross section, corresponding to $80 \%$ relative humidity, is used. A common approach [Kiehl and Briegleb, 1993; Koch et al., 1999; Taylor and Penner, 1994] has been to take a low relative humidity value of the scattering coefficient $\alpha$ of $5 \mathrm{~m}^{2} / \mathrm{g} \mathrm{SO}_{4}{ }^{2-}$ and correct it at more humid conditions by multiplying it by an empirical correction factor $f$, which is a function of relative humidity [Charlson et al., 1984]. Figure 2 shows the aerosol scattering coefficient as a function of relative humidity calculated using this approach along with the results of Mie scattering calculations for comparison. This empirical approach is problematic for several reasons. First, this particular data set extends only up to somewhat less than $90 \%$ relative humidity, which requires that one extrapolate in order to obtain scattering coefficients for more humid conditions. Second, the data are based on ambient samples of aerosols with mixed chemical compositions, and it is not clear to what extent their properties reflect those of sulfate. Finally, the samples are processed in such a way that the measured water uptake corresponds to the rising- $\mathrm{RH}$ portion of the deliquescencecrystallization hysteresis. It is more likely, however, that most aerosol particles exist in the falling- $\mathrm{RH}$, metastable, regime. Other investigators [Chuang et al., 1997; Kiehl et al., 2000; Penner et al., 1998; van Dorland et al., 1997] have computed water uptake based on Köhler theory and used the results as input for their own Mie scattering calculations. This approach avoids the drawbacks just mentioned with regard to the $f(\mathrm{RH})$ approach but still requires assumptions about the dry chemical composition of the aerosol. Although using Köhler theory has the advantage of including the Kelvin effect, this is not important for accumulation mode particles that make the dominant contribution to direct forcing.

Although the aerosol size distribution affects optical properties, it has received little attention in global models because simulating it involves a computationally intensive model of aerosol microphysics and because aerosol optical behavior is less sensitive to uncertainties in particle size than water content [Boucher and Anderson, 1995; Nemesure et al., 1995; Pilinis et al., 1995]. Also, assuming a value for $\alpha$ alleviates the need to describe the size distribution since the

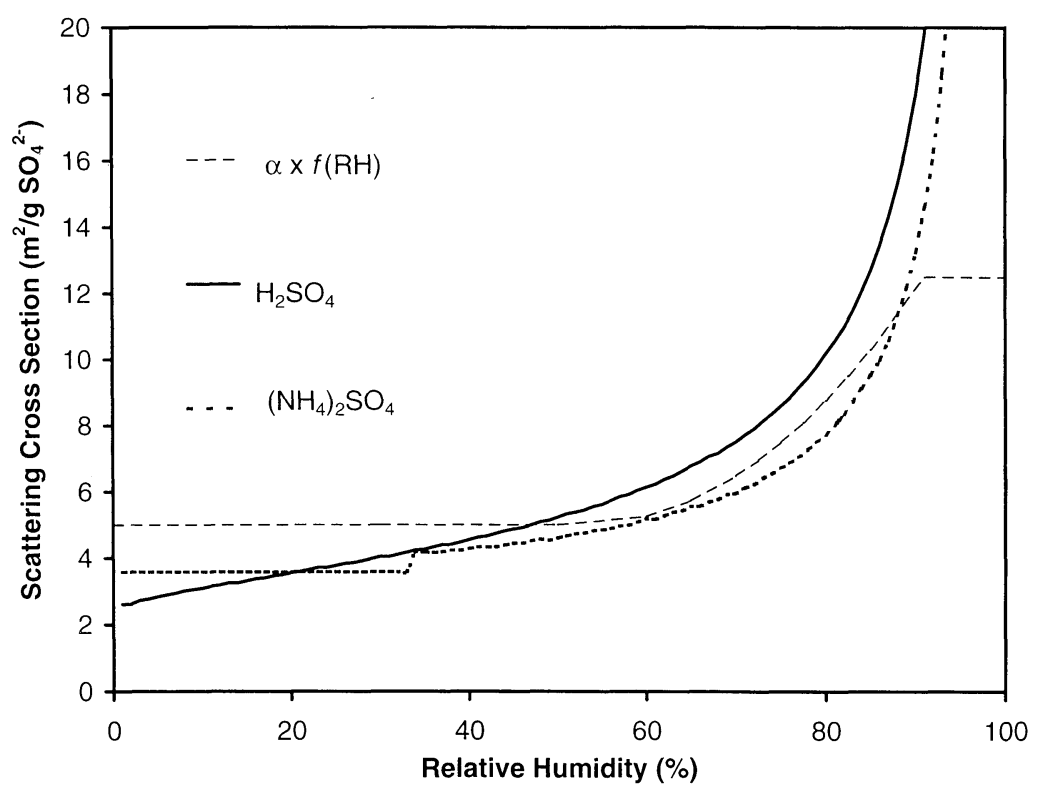

Figure 2. Sulfate aerosol scattering cross sections $\left(\mathrm{m}^{2} / \mathrm{g} \mathrm{SO}_{4}{ }^{2-}\right)$ as a function of relative humidity (\%). Solid lines illustrate optical properties for sulfuric acid and ammonium sulfate computed with the compositiondependent Mie scattering calculations described in this work. For comparison the dashed line represents those computed with the $\alpha \times f(\mathrm{RH})$ parameterization. 
effects of aerosol size are already implicit in the choice of $\alpha$. Explicit description of the aerosol size distribution is necessary only if optical properties are derived from Mie theory. For purposes of Mie calculations, a lognormal distribution of dry particles is invariably assumed in this and previous work, usually with a geometric mean radius of 0.05 $\mu \mathrm{m}$ and a geometric standard deviation of 2.0 , parameters that ensure consistency with observational data.

In this study we simulate the concentrations of sulfate, nitrate, ammonium, and aerosol water in a general circulation model [Adams et al., 1999] to estimate global direct radiative forcing due to tropospheric sulfate and nitrate. Simulating the composition of the aerosol provides an explicit calculation of water uptake based on thermodynamic equilibrium, and therefore the most rigorous estimate of total aerosol mass to date. Aerosol optical properties, such as refractive index and optical depth, are calculated based on predicted composition. This approach alleviates the need for simplifying assumptions such as all sulfate existing as $\left(\mathrm{NH}_{4}\right)_{2} \mathrm{SO}_{4}$ or empirical $f(\mathrm{RH})$ correction factors. Resolving the composition of the sulfate aerosol system therefore improves the description of both its optical properties and its total mass, key uncertainties in previous direct forcing estimates.

The reader should bear in mind that potentially important interactions of sulfate and nitrate with other aerosol types are not yet adequately accounted for in this, or other, global modeling studies. Soot, for example, absorbs solar radiation, but its absorption efficiency is much stronger when internally mixed with sulfate than externally mixed [Haywood et al., 1997b]. Similarly, the presence of mineral dust and sea salt can influence the size distribution of sulfate and, more especially, nitrate by allowing these components to condense into the coarse aerosol mode where they scatter sunlight less efficiently. Therefore the results presented here are just part of the larger problem of aerosol radiative forcing that will ultimately require a more comprehensive and detailed treatment.

We present estimates of direct forcing for the years 1800 (preindustrial), 2000, and 2100 (IPCC Special Report on Emissions Scenarios) (SRES) A2 emissions scenario, preliminary version). All four preliminary IPCC SRES emissions scenarios forecast lower $\mathrm{SO}_{2}$ emissions in 2100 than 2000. We chose to simulate the A2 scenario because it showed the smallest decline in sulfur emissions between 2000 and 2100. Scenario A2 also has the largest increases in $\mathrm{NO}_{x}$ emissions. For each time period a $\mathrm{SO}_{4}{ }^{2-}-\mathrm{NO}_{3}{ }^{-}-\mathrm{NH}_{4}{ }^{+}-\mathrm{H}_{2} \mathrm{O}$ simulation has been compared to a $\mathrm{SO}_{4}{ }^{2-}-\mathrm{NH}_{4}{ }^{+}-\mathrm{H}_{2} \mathrm{O}$ simulation to ascertain how the relative contributions of sulfate and nitrate to direct forcing change over time. The ambient, wet size distributions of these aerosol components are not simulated here but are parameterized in terms of calculated water uptake.

\section{Methodology}

\subsection{Model Description}

The radiative forcing estimates presented here were calculated using a version of the Goddard Institute for Space Studies general circulation model-prime [Hansen et al., 1983; Rind and Lerner, 1996] with an on-line aerosol simulation [Koch et al., 1999; Adams et al., 1999]. The GISS GCM IIprime has a horizontal resolution of 4 degrees latitude by 5 degrees longitude with nine vertical layers between the surface and 10 mbar. The version of the GCM used for this study uses monthly mean ocean temperature maps. The GISS radiation scheme [Lacis and Hansen, 1974; Hansen et al., 1983] uses the correlated $k$ distribution method [Lacis and Oinas, 1991] to compute absorption by gases and particles. Six $k$ intervals, one in the visible region and five near IR, are used for the spectral dependence of Mie parameters of clouds and aerosols for the solar part of the spectrum. Light scattering by aerosols is calculated using the single Gauss point doubling and adding approach. Annual average cloud cover over the course of the simulations was $47 \%$.

This on-line aerosol simulation predicts the concentrations of $\mathrm{H}_{2} \mathrm{O}_{2}$, dimethyl sulfide (DMS), methanesulfonic acid (MSA), $\mathrm{SO}_{2}, \mathrm{NH}_{3}, \mathrm{SO}_{4}{ }^{2-}, \mathrm{NO}_{3}{ }^{-}, \mathrm{NH}_{4}{ }^{+}$, and aerosol water. Gas phase reactions of DMS with $\mathrm{OH}$ and $\mathrm{NO}_{3}$ radicals are included as well as oxidation of $\mathrm{SO}_{2}$ by $\mathrm{OH}$. In-cloud oxidation of $\mathrm{SO}_{2}$ by $\mathrm{H}_{2} \mathrm{O}_{2}$ is also included, but aqueous oxidation by $\mathrm{O}_{3}$ is neglected as it has been estimated to be a much less important pathway in the global sulfur budget [Rasch et al., 2000]. As described by Koch et al. [1999], we use monthly average three-dimensional concentrations fields for the $\mathrm{NO}_{3}$ radical taken from Wang et al. [1998a, 1998b, 1998c] and five day average three-dimensional fields for $\mathrm{OH}$ concentrations. Therefore changes in oxidant availability have been neglected except for changes in $\mathrm{H}_{2} \mathrm{O}_{2}$ resulting from changes in the sulfur cycle.

Aerosol dynamics and composition are treated with a simple bulk model of internally mixed accumulation mode $\mathrm{SO}_{4}{ }^{2-}, \mathrm{NO}_{3}{ }^{-}, \mathrm{NH}_{4}{ }^{+}$, and $\mathrm{H}_{2} \mathrm{O}$. This mixture is assumed to reach thermodynamic equilibrium with the gas phase, a reasonable assumption given the 1-hour model time step [Adams et al., 1999; Meng and Seinfeld, 1996]. The aerosol thermodynamic equilibrium module, ISORROPIA [Nenes et al., 1998], is called by the aerosol simulation every time step to determine the partitioning of the volatile species, ammonia, nitrate, and water, between the gas and aerosol phases based on the prevailing conditions in each model grid cell. For reasons discussed by Adams et al. [1999], we believe that most atmospheric aerosol particles exist in a hydrated, metastable state between their crystallization and deliquescence humidities. Therefore we assume that the upper, metastable branch of the aerosol deliquescencecrystallization hysteresis loop most accurately describes water uptake by atmospheric aerosols.

The model simulates both wet and dry deposition. Gas phase tracers dissolve in cloud water according to their effective Henry's law constants. Aerosol species are assumed to be infinitely soluble. The fate of dissolved tracers generally follows the GCM treatment of liquid water [ $\mathrm{Del}$ Genio and Yao, 1993; Del Genio et al., 1996]. The fraction of cloud water that precipitates and reaches the surface determines the fraction of dissolved tracer that undergoes wet deposition. Alternatively, dissolved tracer may be returned to the gas phase when cloud water evaporates, either in the same model grid cell or another. Below clouds, both aerosols and soluble gases are scavenged according to a first-order parameterization that depends on the amount of precipitation. Dry deposition occurs in the lowest model layer with a deposition velocity computed based on a resistance-in-series scheme [Wesely and Hicks, 1977]. The treatment is similar to that described by Chin et al. [1996] except that the 
aerodynamic resistances depend on the GCM surface momentum and heat fluxes.

The model computes emissions, transport, chemical reactions, and deposition of $\mathrm{H}_{2} \mathrm{O}_{2}, \mathrm{DMS}, \mathrm{MSA}, \mathrm{SO}_{2}, \mathrm{NH}_{3}$, $\mathrm{SO}_{4}{ }^{2-}$, and $\mathrm{NH}_{4}^{+}$. Aerosol nitrate and water are handled somewhat differently. The computational expense of including full tropospheric photochemistry in the model is avoided by importing monthly average nitric acid fields from the Harvard-GISS general circulation model [Mickley et al., 1999], which includes photochemistry as an on-line component in the GISS GCM II-prime. Since the Harvard photochemical model does not distinguish between gas phase and aerosol nitrate, these values are taken to represent the total amount of nitric acid $\left(\mathrm{HNO}_{3}(\mathrm{~g})\right.$ plus aerosol $\left.\mathrm{NO}_{3}{ }^{-}\right)$in a given model grid cell. The aerosol thermodynamic equilibrium module therefore determines what fraction of this total nitric acid occurs as aerosol nitrate depending on local temperature, relative humidity, as well as concentrations of sulfate and ammonia. Thus the model does not compute a budget for aerosol nitrate. Similarly, the aerosol water content is computed thermodynamically based on the relative humidity and aerosol concentrations in the given GCM grid cell.

The concentrations predicted by the model have been compared extensively [Adams et al., 1999] to a wide variety of observations consisting of the Eulerian Model Evaluation Field Study (EMEFS) database [McNaughton and Vet, 1996] for North America, the Co-operative Programme for Monitoring and Evaluation of the Long-Range Transmission of Air Pollutants in Europe (European Monitoring and Evaluation Programme (EMEP)) database [Hjellbrekke and Hanssen, 1998] for Europe as well as numerous other observations of continental and marine areas. Annual average sulfate and ammonium concentrations predicted by the model nearly always agreed with EMEFS and EMEP observations within a factor of 2 . Simulated nitrate concentrations matched observations not quite as well, mostly because the model predicted too much nitrate in polluted continental areas in the winter and too little in marine areas. The overprediction of nitrate in polluted areas during the winter was attributed to high concentrations of ammonia that resulted in excessive ammonium nitrate formation. The low simulated nitrate concentrations in marine areas result from the fact that the model does not capture the condensation of nitric acid onto coarse-mode sea-salt particles.

All runs presented here represent 39-month integrations of the GCM. The first 3 months allow the concentrations of simulated species, which start at zero concentration, to equilibrate to realistic values. The results presented here are average values over the remaining 3 years of simulation. Meteorological quantities are initialized based on output from a previous climate model run. Radiative heating rates used for GCM meteorology were based on no aerosol forcing so aerosol feedbacks on climate were not allowed.

\subsection{Updated Treatment of Ammonia and Nitric Acid}

For purposes of this study, two significant changes have been made to the aerosol model described in Adams et al. [1999]. First, the annual cycle of ammonia emissions has been changed. Emissions of ammonia from livestock, fertilizer application, and crops together constitute nearly two thirds of total emissions [Bouwman et al., 1997] and exhibit a seasonal character. This annual cycle is a result of seasonal changes in livestock housing, the timing of fertilizer application, and the growing season, as well as the dependence of ammonia volatilization on meteorological variables such as temperature and wind speed. In previous studies of the ammonia cycle [Dentener and Crutzen, 1994; Adams et al., 1999], an annual cycle was somewhat arbitrarily applied to these agricultural emissions such that their emission rate was proportional to the number of daylight hours. As mentioned above, this approach results in wintertime ammonia concentrations that are higher than those observed in polluted areas and lead to excessive ammonium nitrate formation. Through trial and error we have found that setting the emission rate of ammonia from agricultural sources proportional to the number of daylight hours to the fourth power results in ammonium and nitrate concentrations that are in substantially better agreement with the observations. Although this treatment may seem unusual and arbitrary, it is not inconsistent with the little that is known about the seasonal cycle of ammonia emissions [Bouwman et al., 1997] and results in predictions that are more consistent with observations than the previous, equally arbitrary, treatment.

Second, the monthly average nitric acid concentration fields have been updated relative to those that were used by Adams et al. [1999]. Instead of importing them from the Harvard Chemical Transport Model (CTM) [Horowitz et al., 1998], also based on GISS GCM meteorology, but with offline photochemistry, we use the on-line version known as the Harvard-GISS GCM [Mickley et al., 1999]. Updating the nitric acid fields has two advantages. First, it improves the overall consistency of the model because the Harvard-GISS GCM photochemical model is based on the same version of the GISS GCM II-prime as this work. Second, the HarvardGISS GCM has been used to simulate the photochemistry of the preindustrial atmosphere and its results have been compared to the few observations that are available from that time period. The Harvard-GISS GCM can therefore provide a set of monthly average nitric acid concentration fields for the preindustrial period that allows us to examine how direct forcing by nitrate aerosol has changed since the Industrial Revolution. There are, however, significant differences between the newer Harvard-GISS GCM fields and the older Harvard CTM fields. The newer nitric acid (gas plus aerosol) concentrations are higher than the older ones by only $20 \%$ in the model surface layer but are more than 3 times higher above about 500 mbar.

Both the new annual cycle of agricultural ammonia emissions and the new nitric acid (gas plus aerosol) fields have noticeably altered the predicted aerosol ammonium and nitrate concentrations. Most important for this work is the fact that the nitrate burden resulting from the newer nitric acid fields, $0.09 \mathrm{Tg} \mathrm{N}$, is 3 times that reported by Adams et al. [1999]. Most of the increased burden is above the boundary layer, a reflection of where the new nitric acid fields show the greatest increase. Nitrate concentrations in the model surface layer increase by only $20 \%$ on average over those found by Adams et al. [1999]. This results in slightly poorer agreement with observations, but does not radically undermine our confidence in model performance, especially considering the difficulties and uncertainties inherent in measuring a volatile aerosol component such as nitrate. These changes have a 
relatively smaller impact on simulated ammonium concentrations. The new ammonium burden, $0.42 \mathrm{Tg} \mathrm{N}$, is $40 \%$ greater than the one previously reported. The increased ammonium burden results partly from the increased nitrate burden and partly from increased ammonia emissions during summer. Sulfate concentrations tend to be highest during the summertime such that ammonia is more likely to be converted to longer-lived aerosol ammonium during that time of year. As was the case with nitrate, the most dramatic increases occur higher up in the troposphere with ammonium concentrations doubling at 200 mbar. At the surface, ammonium concentrations increase by only $15 \%$ on average, which causes no concern given the good agreement with observations.

\subsection{Aerosol Optical Properties}

The optical properties of the aerosol mixture have been computed using Mie scattering theory in such a way that they realistically reflect changes in aerosol composition and water uptake. Mie scattering calculations require knowledge of the aerosol refractive index to compute single-particle scattering and absorption cross sections for any given particle size. Given a collection of particles of various sizes, one can integrate over the aerosol size distribution to calculate average scattering and absorption cross sections for the entire aerosol population. These quantities, typically expressed in $\mathrm{m}^{2} / \mathrm{g}$, combined with the column burden of aerosol, give the corresponding optical depths. We ignore absorption of radiation by aerosols, an excellent approximation for the mixture of sulfate, nitrate, ammonium, and water treated here.

We use the method of partial molar refraction [Stelson, 1990] to compute the refractive index of the aerosol mixture present in a given GCM grid cell at a given time step based on laboratory measurements of single-component aerosol optical properties [Tang and Munkelwitz, 1994; Tang, 1996, 1997]. Given that this model, like other global aerosol models, does not resolve the aerosol size distribution, one must be assumed for purposes of calculating aerosol optical properties. In common with nearly every other study that uses Mie theory to generate the optical properties, we assume a lognormal size distribution of dry particles having a geometric mean radius of $0.05 \mu \mathrm{m}$ and geometric standard deviation of 2.0. Water uptake is taken into account by means of a "mass growth factor", defined as the ratio of wet aerosol mass to dry aerosol mass as calculated by the aerosol thermodynamic equilibrium module. This mass growth factor is converted into a similarly defined diameter growth factor given data on the dry and wet aerosol densities [Tang and Munkelwitz, 1994; Tang, 1996, 1997]. The diameter growth factor is used to calculate the geometric mean radius of the wet size distribution. The geometric standard deviation remains unchanged. Therefore the model does not explicitly simulate the aerosol size distribution but parameterizes it in terms of an assumed dry lognormal distribution and the amount of water uptake in a given GCM cell.

Assuming that the nitrate aerosol we simulate is present in the accumulation mode size range requires some justification. The range of particle sizes in which nitrate aerosol might occur is expected to depend strongly on the cation with which it is associated. When nitrate reacts with sodium in sea-salt aerosol or cations in mineral dust, it will be found in the larger particle size range characteristic of these aerosol types.
We do not treat sea salt or mineral dust in this model, however, so these kinds of nitrate are neglected in this work. On the other hand, the formation of ammonium nitrate occurs when gas phase ammonia and nitric acid condense onto whatever aerosol happens to be at hand. In the polluted continental regions in which most of the nitrate in this model occurs, one expects that ammonium and nitrate will condense primarily onto particles in the submicron size range. Since nitrate in supermicron sized particles scatters light less efficiently, we will tend to overestimate the nitrate forcing to the extent that our assumption breaks down. On the other hand, the fact that this model does not capture nitrate associated with sea salt or mineral dust will cause us to underestimate the nitrate forcing somewhat. Overcoming these drawbacks will ultimately require a size-resolved aerosol simulation that treats sea salt and mineral dust as well.

Mie scattering calculations were performed off-line to generate scattering cross sections and asymmetry parameters for a variety of aerosol refractive indices and mass growth factors (i.e., size distributions). These were compiled into a lookup table such that the appropriate scattering cross section and asymmetry parameter for any given aerosol mixture could be rapidly retrieved during GCM runs. The aerosol optical depth for a given GCM grid cell is computed as the product of the local scattering cross section and aerosol burden and is passed to the GCM radiation scheme.

Figure 2 shows sample scattering cross sections for ammonium sulfate and sulfuric acid as a function of relative humidity. These are shown for purposes of illustration only. In general, a GCM grid cell will contain a more complicated mixture that includes nitrate. For comparison the cross sections one would compute by taking a low relative humidity scattering coefficient of $5 \mathrm{~m}^{2} / \mathrm{g} \mathrm{SO}_{4}{ }^{2-}$ and correcting with the empirical $f(\mathrm{RH})$ factor described above are also shown. This approach agrees fairly well with our results for ammonium sulfate at intermediate relative humidities, but important discrepancies should be noted. Most importantly, the empirical data upon which the $f(\mathrm{RH})$ factor is based extend only a little past $85 \% \mathrm{RH}$. At higher relative humidities, scattering cross sections have been taken as constant in previous work that uses the $f(\mathrm{RH})$ correction. Our results show very substantial water uptake and higher scattering cross sections per unit sulfate at higher relative humidities. We will discuss later the sensitivity of overall direct aerosol forcing to the contribution made by water uptake at high relative humidity and the difficulty in representing this in GCMs. Similarly, it should be noted that the low relative humidity value of $5 \mathrm{~m}^{2} / \mathrm{g} \mathrm{SO}_{4}{ }^{2-}$ is appropriate for a relative humidity of about $50 \%$ and overestimates scattering at drier conditions. Finally, this parameterization of optical properties cannot distinguish between ammonium sulfate and sulfuric acid, nor account for the presence of nitrate in the mixture.

\subsection{Emissions Scenarios}

Several simulations have been performed to ascertain the anthropogenic aerosol forcing resulting from industrialization, project how forcing might change as the century progresses, determine the relative contributions of sulfate and nitrate, and the sensitivity to water uptake at high relative humidity. Three different time periods have been simulated: preindustrial (roughly corresponding to the year 1800), modern day (year 2000), and the year 2100. Table 1 
Table 1. A Summary of Emissions, Input Nitric Acid Concentrations, Aerosol Burdens and Forcings for the Three Time Periods Simulated in This Study.

\begin{tabular}{|c|c|c|c|c|}
\hline & & \multicolumn{3}{|c|}{ Scenario } \\
\hline & & $\begin{array}{c}\text { Preindustrial } \\
1800 \\
\end{array}$ & $\begin{array}{l}\text { Modern Day } \\
2000\end{array}$ & $\begin{array}{c}\text { IPCC SRES A2 } \\
2100 \\
\end{array}$ \\
\hline \multicolumn{5}{|c|}{ Emissions } \\
\hline \multirow[t]{3}{*}{$\mathrm{SO}_{2}, \mathrm{Tg} \mathrm{S} / \mathrm{yr}$} & Total & 4.8 & 73.8 & 65.1 \\
\hline & Anthropogenic & 0.0 & 69.0 & 60.3 \\
\hline & Volcanic & 4.8 & 4.8 & 4.8 \\
\hline DMS, Tg S/yr & & 26.0 & 26.0 & 26.0 \\
\hline $\mathrm{NO}_{x}, \mathrm{Tg} \mathrm{N} / \mathrm{yr}^{\mathrm{a}}$ & & 8.6 & 32.5 & 109.7 \\
\hline \multirow[t]{23}{*}{$\mathrm{NH}_{3}, \mathrm{Tg} \mathrm{N} / \mathrm{yr}$} & Total & 18.7 & 57.6 & 122.2 \\
\hline & Agricultural $^{\mathrm{b}}$ & 6.8 & 37.4 & 88.8 \\
\hline & Natural $^{\mathrm{c}}$ & 10.7 & 10.7 & 10.7 \\
\hline & Biomass burning & 0.6 & 6.4 & 15.3 \\
\hline & Other ${ }^{\mathrm{d}}$ & 0.6 & 3.1 & 7.4 \\
\hline & Annual Average $H$ & $\mathrm{VO}_{3}$ Concentra & $n s, p p t v$ & \\
\hline & Surface layer & 59 & 356 & 1022 \\
\hline & 634 mbar & 119 & 292 & 648 \\
\hline & 201 mbar & 317 & 465 & 884 \\
\hline & \multicolumn{4}{|c|}{ Aerosol Burdens, $T g$} \\
\hline & Total & 4.05 & 12.78 & 20.55 \\
\hline & $\mathrm{SO}_{4}{ }^{2-}$ & 0.74 & 2.41 & 2.23 \\
\hline & $\mathrm{NO}_{3}{ }^{-}$ & 0.10 & 0.38 & 1.79 \\
\hline & $\mathrm{NH}_{4}^{+}$ & 0.12 & 0.54 & 1.04 \\
\hline & $\mathrm{H}_{2} \mathrm{O}$ & 3.11 & 9.45 & 15.48 \\
\hline & \multicolumn{4}{|c|}{ Direct Forcings, $\mathrm{W} / \mathrm{m}^{2}$} \\
\hline & Total & -0.63 & -1.78 & -2.77 \\
\hline & $\mathrm{SO}_{4}{ }^{2-}$ & -0.52 & -1.48 & -1.38 \\
\hline & $\mathrm{NO}_{3}^{-}$ & -0.11 & -0.30 & -1.39 \\
\hline & \multicolumn{4}{|c|}{ Anthropogenic Forcings, $\mathrm{W} / \mathrm{m}^{2}$} \\
\hline & Total & N/A & -1.14 & -2.13 \\
\hline & $\mathrm{SO}_{4}{ }^{2-}$ & N/A & -0.95 & -0.85 \\
\hline & $\mathrm{NO}_{3}{ }^{-}$ & N/A & -0.19 & -1.28 \\
\hline
\end{tabular}

${ }^{\mathrm{a}} \mathrm{NO}_{x}$ emissions are those used in the Harvard-GISS GCM [Mickley et al., 1999]. Although not used directly in this work, they are presented to explain the trend in and assumptions behind the input nitric acid concentrations taken from this model.

${ }^{\mathrm{h}}$ Agricultural emissions include the following categories from Bouwman et al. [1997]: domestic animals, synthetic fertilizers, and crops.

${ }^{c}$ Natural emissions include the following categories from Bouwman et al. [1997]: oceans, undisturbed soils, and wild animals.

${ }^{d}$ Other emissions include the following categories from Bouwman et al. [1997]: humans and pets, industrial processes and fossil fuels.

summarizes sulfur and ammonia emissions as well as nitric acid fields for all three time periods. Note that all IPCC SRES emissions data are based on the preliminary versions of the scenarios.

For each run the appropriate set of nitric acid concentration fields was taken from the Harvard-GISS GCM. The simulations that produced the preindustrial and modern day fields are documented by Mickley et al. [1999]. The year 2100 nitric acid fields were taken from a Harvard-GISS GCM run based on the IPCC SRES A2 emissions scenario. Given the uncertainty in projecting nitric acid concentrations 100 years into the future, the year 2100 run was repeated with nitric acid fields from the Oslo CTM1 [Berntsen and Isaksen, 1997; Jaffe et al., 1997]. Although these nitric acid fields were distinctly different than those from the Harvard-GISS
GCM, the resulting aerosol nitrate burden and forcing was not substantially different and will not be presented here.

Sulfur emissions for the modern day and year 2100 run were also prescribed based on the IPCC SRES A2 emissions scenario. Preindustrial sulfur emissions included only DMS emissions from the oceans and volcanic $\mathrm{SO}_{2}$ emissions. DMS emissions are assumed to be the same in all three time periods. This neglects the possibility that changes in wind patterns and speeds induced by climate change over the next century may influence emissions of trace gases from the ocean. More generally, the same climate was used to simulate all three time periods. The effects of climate changes on aerosol chemistry, transport, and deposition are therefore neglected but are expected to be small compared to the effect of changes in anthropogenic emissions. Volcanic emissions 


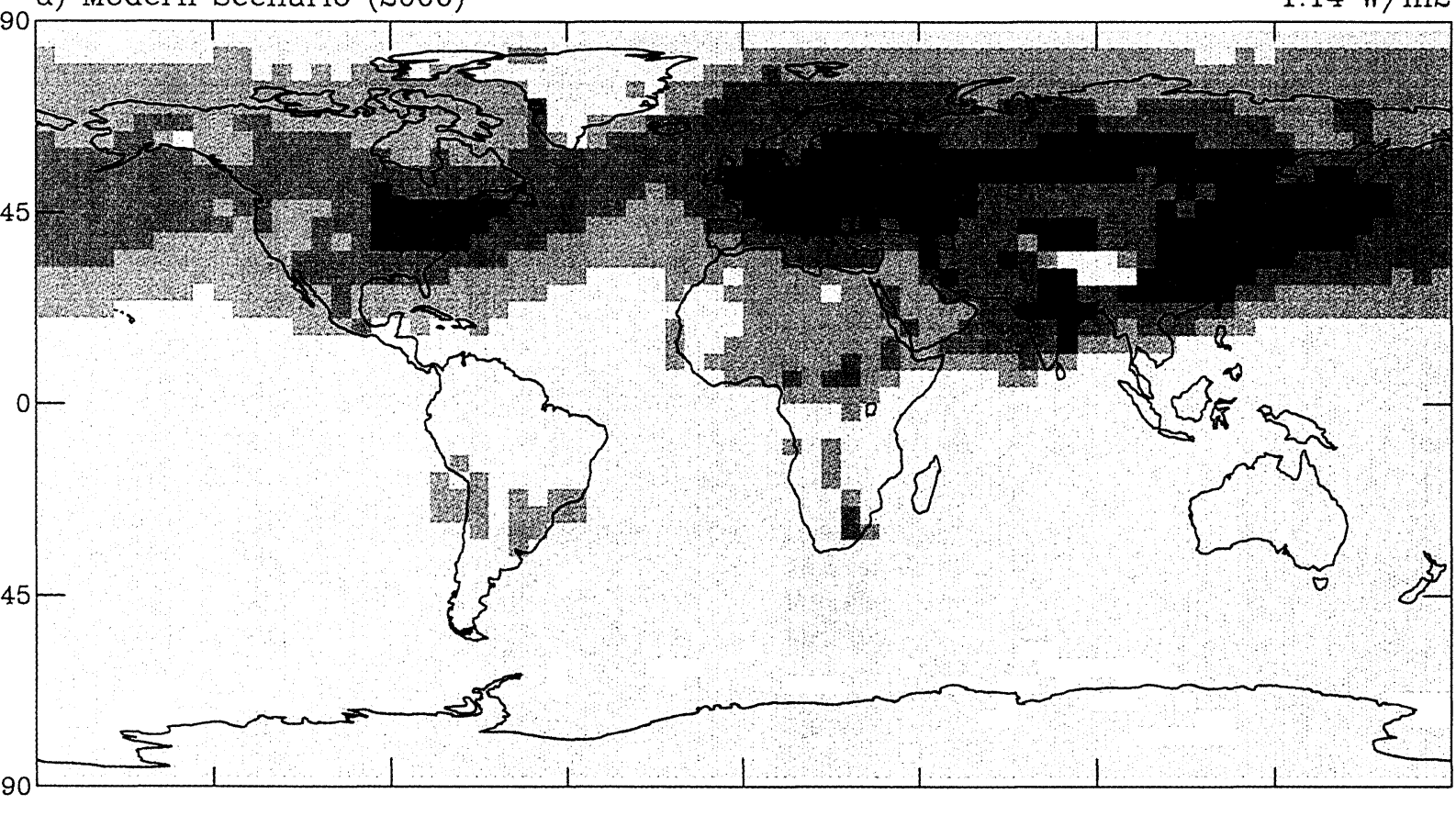

b) IPCC SRES A2 Future Scenario (2100)

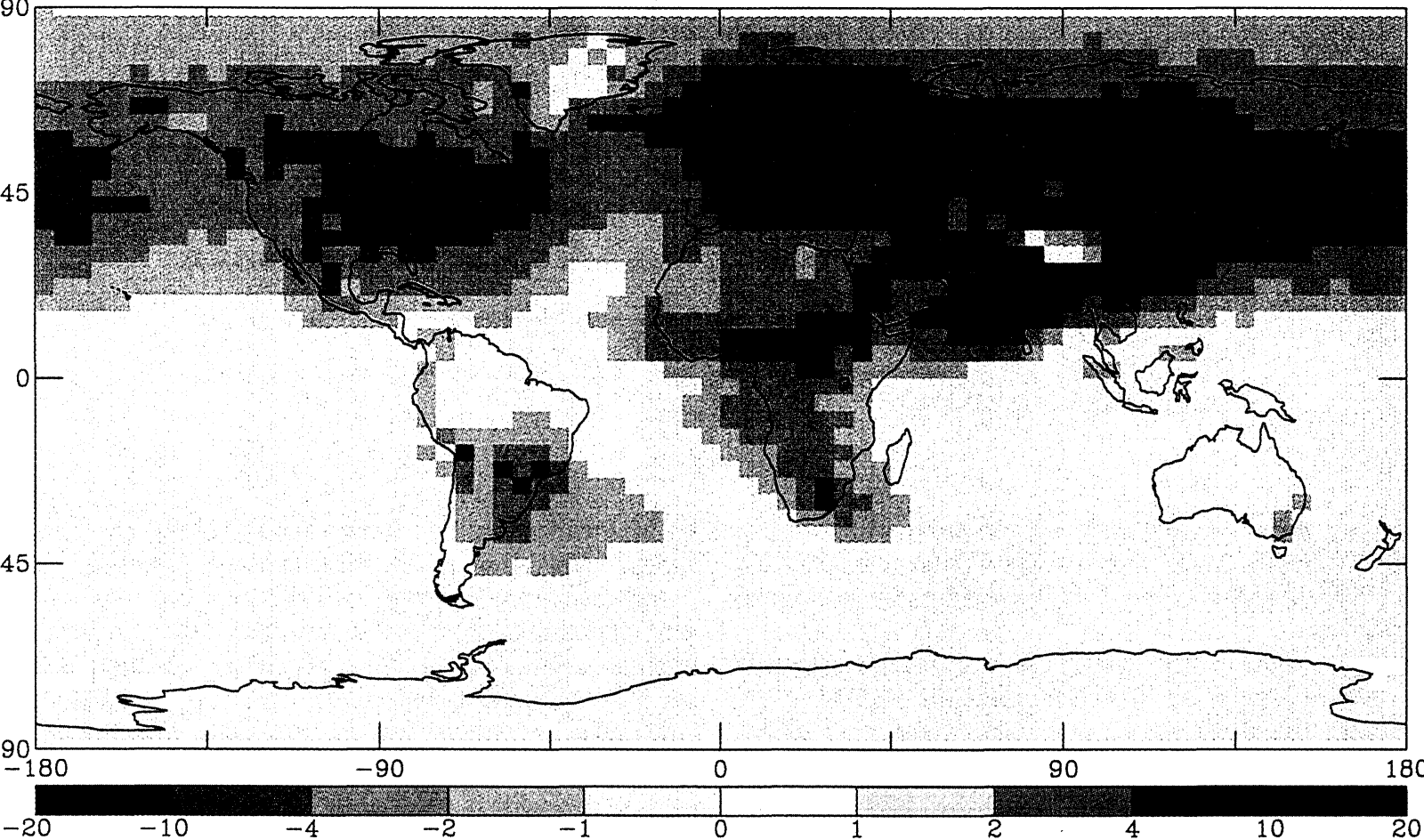

Plate 1. Geographic distribution of annual average anthropogenic total (sulfate and nitrate) direct aerosol forcing $\left(\mathrm{W} / \mathrm{m}^{2}\right)$ for (a) modern day (2000) and (b) future (2100) emissions scenarios. Values in the upper right corner of each map show the corresponding global average forcing. 


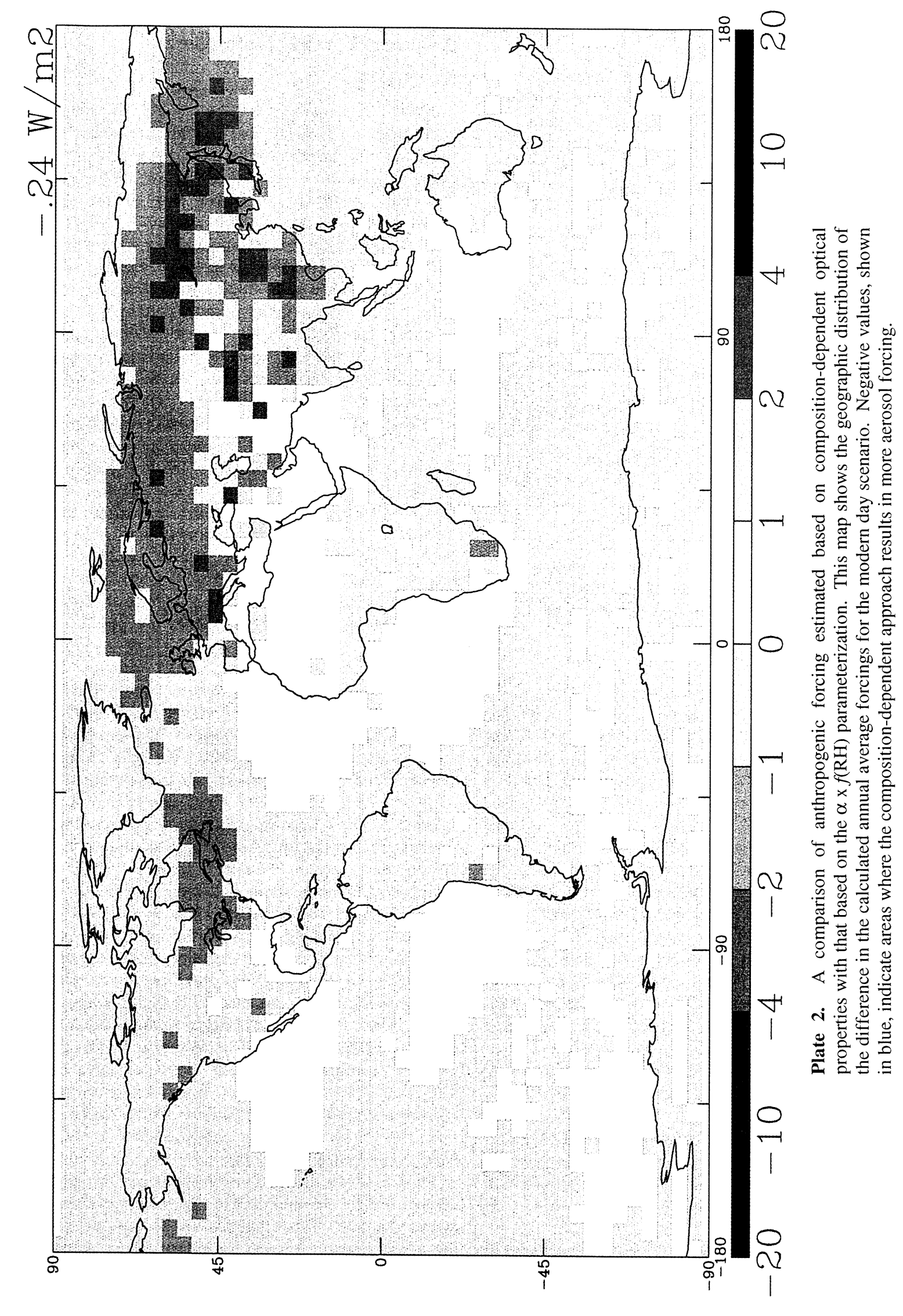


of $\mathrm{SO}_{2}$ are estimated to be $4.8 \mathrm{Tg} \mathrm{S} / \mathrm{yr}$ in all scenarios [Andres and Kasgnoc, 1998]. Current sulfur emissions are estimated to be more than 3 times greater than their preindustrial levels but decline slightly from their present-day value by the year 2100 .

Little work has been done on past and future ammonia emissions, so several assumptions were required. Ammonia emissions for all three time periods were based on the Global Emissions Inventory Activity (GEIA) [Bouwman et al., 1997], which provides emissions for the year 1990, with appropriate modifications for 1800,2000 , and 2100. Natural emissions of ammonia from the oceans, undisturbed soils, and wild animals were assumed to be unchanged between 1800 and 2100. Although changes in land use are expected to affect the last two substantially, the oceans are the only natural source that contributes significantly to total ammonia emissions. Emissions from synthetic fertilizers, industrial processes, and fossil fuels were excluded in the preindustrial run. Emissions from biomass burning were set to $10 \%$ of their present value [Crutzen and Zimmermann, 1991]. Emissions from livestock, crops, humans, and pets were assumed to be proportional to human population, which was taken to be $20 \%$ of the presentday value in 1800 . Considering that agriculture is the main anthropogenic source of both $\mathrm{N}_{2} \mathrm{O}$ and ammonia emissions, anthropogenic ammonia emissions for the years 2000 and 2100 were scaled with the $\mathrm{N}_{2} \mathrm{O}$ emissions prescribed in the IPCC SRES A2 scenario (Frank Dentener, personal communication, 1999). Given these assumptions, we estimate that ammonia emissions increase from $18.7 \mathrm{Tg} \mathrm{N} \mathrm{yr}^{-1}$ in 1800 to $57.6 \mathrm{Tg} \mathrm{N} \mathrm{yr}^{-1}$ in 2000 to $122.2 \mathrm{Tg} \mathrm{N} \mathrm{yr}^{-1}$ by the year 2100 .

\subsection{Sensitivity Runs}

In addition to the base case runs described above for each time period, several sensitivity runs were performed. First, for each time period a sensitivity run was performed in which nitrate aerosol concentrations were assumed to be zero. These allow us to determine how much of the overall aerosol forcing can be attributed to nitrate and also facilitate comparison with other published results based on models that only consider sulfate. The "nitrate forcing" is taken as the difference in forcing between runs with and without nitrate. It should be stressed, however, that sulfate and nitrate engage in a competition for available ammonia such that the total aerosol mass or forcing is a nonlinear function of either concentration [Ansari and Pandis, 1998; West et al., 1998]. For example, a decline in sulfate concentrations frees ammonia that can react with nitric acid and result in enhanced ammonium nitrate concentrations.

Also, a sensitivity run was performed for each of the three time periods in which the forcing was calculated based only on the sulfate concentration with a low RH scattering coefficient of $5 \mathrm{~m}^{2} / \mathrm{g} \mathrm{SO}_{4}{ }^{2-}$ corrected with an empirical $f(\mathrm{RH})$ factor. This lets us compare the forcing that results from the fundamental thermodynamic model of aerosol composition used here to the approximate approach sometimes seen in the literature.

Finally, the sensitivity of aerosol forcing to water uptake at high relative humidities was explored in a series of three sensitivity runs in which the maximum aerosol water uptake was varied. In the base case scenario, aerosol water uptake was limited to that which occurred at a value of $99 \% \mathrm{RH}$. In the sensitivity runs, this value was set at $85 \%, 90 \%$, and $95 \%$.

\section{Direct Forcing Estimates}

\subsection{Overview}

Table 1 summarizes the emissions, input $\mathrm{HNO}_{3}$ concentrations, burdens, and forcings calculated for each of the three time periods. The total direct aerosol forcing for each simulation is computed as the difference in net downward shortwave radiative flux at the top of the atmosphere with and without aerosols. Although sulfate aerosols can also absorb thermal radiation, the results of Lacis and Mishchenko [1995] show that the thermal forcing is just a few percent of the solar forcing for sulfate aerosols up to 3 $\mathrm{km}$. Some of the direct aerosol forcing is the result of naturally occurring aerosols. We calculate the anthropogenic component of the forcing as the additional forcing found in the 2000 and 2100 scenarios when compared with the preindustrial scenario. Besides apportioning the direct forcing into natural and anthropogenic components, we also break it down according to chemical species. Our base case scenarios include the effects of both sulfate and nitrate. Sensitivity scenarios with only sulfate allow us to calculate the sulfate forcing; the remainder is considered to be nitrate forcing. Although aerosol ammonium and water play important roles in determining direct radiative forcing, no portion of the forcing is ascribed to them because they exist in the aerosol phase only by virtue of sulfate or nitrate. Unless stated otherwise, all forcing values are global and annual averages.

Present-day anthropogenic direct aerosol forcing is estimated to be $-1.14 \mathrm{~W} / \mathrm{m}^{2}$, counting contributions from both sulfate and nitrate, which are found to be -0.95 and -0.19 $\mathrm{W} / \mathrm{m}^{2}$, respectively. This estimate is significantly higher than most recent published estimates for two reasons. First, calculating the aerosol optical properties based upon the thermodynamic equilibrium water uptake shows that water uptake at high relative humidity contributes strongly to the radiative forcing, a contribution that has often been neglected in previous work. Second, nitrate, along with the accompanying ammonium and water, makes a small, but noticeable contribution. The effect of nitrate is even more important in the IPCC scenario for the year 2100. In this scenario, decreases in sulfur emissions lead to a slightly lower sulfate forcing of $-0.85 \mathrm{~W} / \mathrm{m}^{2}$, but increases in $\mathrm{NO}_{x}$ and $\mathrm{NH}_{3}$ emissions result in a dramatic increase in nitrate forcing to $-1.28 \mathrm{~W} / \mathrm{m}^{2}$. These results demonstrate that, over the next century, ammonium nitrate aerosol could alter the Earth's radiative balance to an even larger extent than sulfate. Therefore GCM simulations of future climate changes need to take into account radiative forcing due to nitrate as well as other aerosol species and greenhouse gases that have already been recognized as significant.

Plate 1 shows the geographical pattern of anthropogenic aerosol forcing for the modern day and year 2100 scenarios considered here. This figure shows the expected pattern with the most aerosol forcing in industrialized areas such as eastern North America, Europe, and eastern Asia. Annual average anthropogenic aerosol forcings exceed $-4 \mathrm{~W} / \mathrm{m}^{2}$ across these areas for the present-day scenario and are 
projected to exceed $-10 \mathrm{~W} / \mathrm{m}^{2}$ in smaller areas by the year 2100. The increased forcing in the year 2100 is especially dramatic over India and China. This is mostly a result of higher emissions of $\mathrm{NO}_{x}$ and ammonia leading to high concentrations of ammonium nitrate aerosol but also results partly from increased sulfate concentrations over India.

\subsection{Water Uptake}

It has already been mentioned that parameterizing sulfate scattering behavior in terms of a low relative humidity value for $\alpha$ and a high relative humidity correction factor $f(\mathrm{RH})$ yields different results than the method adopted here. Specifically, the $\alpha$ and $f(\mathrm{RH})$ method underestimates scattering cross sections at relative humidities greater than about $85 \%$ and overestimates them at low humidity. It also neglects differences between sulfate that is neutralized by ammonia and that which is not. We have performed side by side forcing calculations using each method to assess how much impact these discrepancies have on the global and annual average forcing. To facilitate comparison, this has been accomplished in the sensitivity runs in which nitrate was ignored.

We find a present-day anthropogenic sulfate forcing of $0.71 \mathrm{~W} / \mathrm{m}^{2}$ using the $\alpha$ and $f(\mathrm{RH})$ method, considerably lower than the $-0.95 \mathrm{~W} / \mathrm{m}^{2}$ value found using our standard method. The main reason for the difference is the additional water uptake at high relative humidity that is neglected by the $f(\mathrm{RH})$ parameterization. This water makes a significant contribution to the total forcing despite the fact that the clouds that are typically present at high relative humidity partially mask its effect. Previous aerosol forcing studies in the GISS GCM [Lacis and Mischenko, 1995] indicate that the presence of clouds reduces the magnitude of aerosol forcing by a factor of 3.5 relative to its clear-sky value. However, the aerosol extinction coefficient increases in magnitude by a similar factor between $90 \%$ and $99 \% \mathrm{RH}$. Therefore an aerosol particle at $99 \% \mathrm{RH}$ in a cloudy region and another at $90 \% \mathrm{RH}$ in clear skies will have about the same forcing efficiency. Our finding that water uptake at high relative humidities makes a significant contribution to global and annual average forcing agrees with the findings of Kiehl et al. [2000], where aerosol water uptake is calculated using Köhler theory. Although that model does not include nitrate nor take into account variations in ammonium content, the resulting scattering coefficients depend on relative humidity in a manner that is similar to those used here. Compared to the $\alpha$ and $f(\mathrm{RH})$ parameterization used in their previous work, they found that the additional aerosol water uptake above $90 \%$ relative humidity resulted in a estimated direct forcing that was approximately $50 \%$ greater.

Plate 2 shows the spatial distribution of the difference in anthropogenic forcing between the two methods for the modern day scenario. The difference is negative in most areas, indicating that the current more rigorous approach results in more aerosol forcing than the $f(\mathrm{RH})$ parameterization. The magnitude of the discrepancy is generally less than $1 \mathrm{~W} / \mathrm{m}^{2}$, but exceeds $2 \mathrm{~W} / \mathrm{m}^{2}$ over parts of the Northern Hemisphere. The figure also shows, however, subtropical regions in which the opposite is true. This occurs because the free troposphere above these regions is relatively dry. At these low relative humidities we calculate that the average aerosol scattering cross section is even lower than the minimum value of $5 \mathrm{~m}^{2} / \mathrm{g} \mathrm{SO}_{4}{ }^{2-}$ assumed in the $f(\mathrm{RH})$ parameterization. Therefore how one chooses to represent aerosol water uptake in a global model not only influences the global and annual average aerosol forcing but also significantly modifies the geographical distribution of the forcing. Moreover, the effect of higher relative humidities is more pronounced in winter months so the temporal distribution is affected as well.

As previously noted, in the base case scenario we limited aerosol water uptake to that which occurs at $99 \% \mathrm{RH}$. At such high relative humidities, subgrid-scale effects may be especially important and problematic. For example, in humid, cloudy areas, cloud cover, relative humidity, and aerosol optical depth will be correlated on length scales that GCMs do not resolve. These unresolved correlations may result in systematic biases in GCM estimates of aerosol forcing. For example, the GISS GCM II-prime assumes a uniform aerosol optical depth across a grid cell but allows for cloudy and clear fractions in the same grid cell. Intuitively, one would expect the clear portion of the grid cell to have a lower average humidity and resulting aerosol optical depth than the cloudy portion. Because a small relative humidity difference can have a large effect on aerosol optical depth and because clouds mask some of the aerosol forcing, these effects could be important. Aithough a grid cell with a high relative humidity will certainly have a substantial cloudy portion that partly masks the aerosol forcing, the aerosol optical depth specified for the clear portion may be based on a grid cell average relative humidity that is too high for the clear portion. This could exaggerate the aerosol forcing. One, somewhat unsatisfying, way to compensate for this bias would be to specify a RH cutoff that prevents unrealistically high $\mathrm{RH}$ and aerosol optical depths in clear areas. It is not obvious, however, what RH cutoff is most appropriate. Published estimates of aerosol forcing typically say little, if anything, about the choice of relative humidity cutoff. This is unfortunate because the global and annual average forcing is very sensitive to water uptake at high $\mathrm{RH}$ and whether the choice of RH cutoff allows this water uptake.

We performed sensitivity studies to evaluate the effect of different RH cutoff values. Figure 3 shows global and annual average direct forcing estimates for the modern day, sulfateonly scenario as a function of RH cutoff. For comparison the forcing obtained from the $f(\mathrm{RH})$ method is similar to that obtained with a 95\% RH cutoff. What is striking about the figure is that the rise in aerosol forcing between $85 \%$ and $95 \% \mathrm{RH}$ is a little bit less than $20 \%$. The jump between $95 \%$ and $99 \%$ RH, however, is much more substantial, nearly $60 \%$. Penner et al. [1998] describe a similar result in which increasing their $\mathrm{RH}$ from $90 \%$ to $99 \%$ increases the calculated forcing by $50 \%$. This sensitivity in both models results from the exponential-like water uptake behavior of the aerosol at high relative humidity but also indicates that many GCM grid cells spend a significant amount of time at these high relative humidities. It is not clear whether these GCM humidity distributions are realistic. Whereas water uptake by aerosols at high relative humidity is well understood and quantified, the ability of GCMs to represent very humid conditions is questionable. Evaluation of hydrological schemes for GCMs has tended to focus on obtaining realistic precipitation and cloud cover. Relative humidity values may not be as well simulated in GCMs, a potential problem for aerosol forcing calculations considering the sensitivity shown here. 


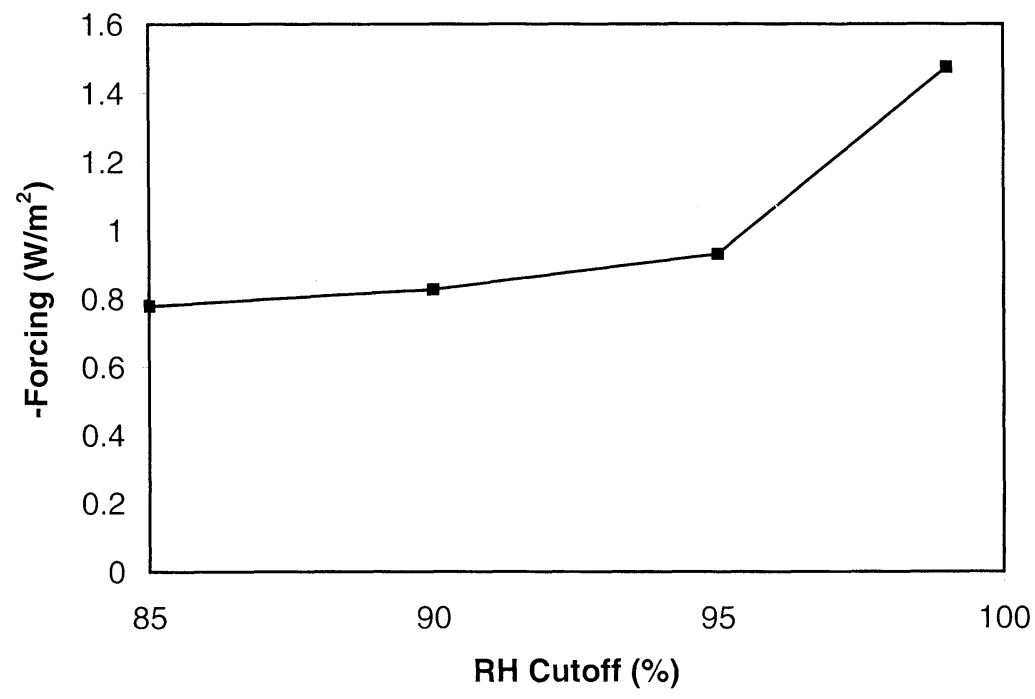

Figure 3. Sensitivity of global and annual average aerosol forcing to relative humidity cutoff. The RH cutoff limits aerosol water uptake to the amount that occurs at that $\mathrm{RH}$ value.

The sensitivity of the forcing to aerosol behavior at high relative humidity naturally raises questions about how well the GISS GCM II-prime or any GCM can represent this behavior. For example, one expects substantial subgrid variability in the relative humidity. Given the nonlinear dependence of aerosol scattering on relative humidity, calculations based on the grid cell average humidity may contain systematic biases. Moreover, clouds will frequently occur in grid cells with high average relative humidity. Subgrid variation in cloudiness, relative humidity, and aerosol optical depth as well as potential correlations in these variables will not be captured in the GCM but may be important. The GISS GCM II-prime radiation scheme used in this study, for example, allows cloudy and clear areas to exist within the same grid cell but assumes uniform relative humidity and aerosol optical depth across a given grid cell.

Haywood et al. [1997a] provide partial answers to these questions. They used a limited-area model with $2 \mathrm{~km}$ by $2 \mathrm{~km}$ horizontal resolution to compute aerosol forcing and then compared their results with those based on GCM-scale average quantities. The meteorological conditions chosen for this comparison were humid areas (93\% average $\mathrm{RH}$ ) with scattered convective clouds covering approximately one third of the domain. They found that the GCM calculations underestimate direct radiative forcing by $73 \%$ under their clear-sky conditions and by $60 \%$ in cloudy regions. The discrepancy results from the nonlinearity in water uptake at high relative humidities that causes the forcing calculated from the average humidity across a GCM grid cell to be less than that calculated from a distribution of humidities within a grid cell. In this study the presence of clouds reduced this effect slightly but did not eliminate it entirely. These results show that GCM calculations of direct forcing may underestimate the forcing because of subgrid-scale variations in relative humidity, although one does not expect these effects to be as dramatic in less humid or more cloudy conditions. Therefore even the forcing estimates presented here, though high in comparison with other global models, may underestimate the aerosol forcing. Many questions remain, however, and more work clearly needs to be done to improve the representation of direct forcing in GCMs.

As noted above, we assume that atmospheric aerosol particles exist in a hydrated, metastable state between their crystallization and deliquescence humidities. Although we believe that this is the mostly likely situation under most atmospheric conditions, it is conceivable that some air parcels experience low enough relative humidity to provoke crystallization. Assuming metastability will overestimate water uptake and direct forcing to the extent that this assumption breaks down. This is not expected to occur frequently, however. Pure ammonium sulfate crystallizes only below $40 \% \mathrm{RH}$, ammonium bisulfate and ammonium nitrate below $10 \% \mathrm{RH}$, and sulfuric acid is hydrated at all values of RH. Therefore only nearly pure ammonium sulfate is expected to crystallize under very dry conditions. Our results show that, globally averaged, the molar ratio of ammonium to sulfate is close to one. Only in limited areas such as the tropics, Europe, China, and India is sulfate substantially neutralized such that it might have a high crystallization $\mathrm{RH}$ similar to that of pure ammonium sulfate. In such areas, conditions would usually be too humid for crystallization. Therefore crystallization of sulfate aerosol is not expected to occur frequently in the atmosphere. Moreover, Boucher and Anderson [1995] have shown that, for a pure ammonium sulfate aerosol, the difference in global and annual average forcing between the rising and falling branches of the hysteresis loop is only $18 \%$. This is an upper bound on the error introduced by our assumption of metastable aerosol. Considering that nearly pure ammonium sulfate is not often found in dry areas, we expect the actual error to be much lower.

\subsection{Comparison With Other Work}

To put these results in the context of previously reported work, we refer back to Figure 1, which shows published estimates of anthropogenic direct forcing as a function of anthropogenic sulfate burdens. When we consider only sulfate and parameterize its optical properties in terms of a 
low $\mathrm{RH} \alpha$ and a $f(\mathrm{RH})$ factor, we obtain a forcing estimate of $-0.71 \mathrm{~W} / \mathrm{m}^{2}$. As expected, this matches very closely the $0.68 \mathrm{~W} / \mathrm{m}^{2}$ found by Koch et al. [1999], which is based on the same sulfur model and uses the same $\alpha$ and $f(\mathrm{RH})$ parameterization of sulfate optical properties. However, when we compute the radiative forcing based on the concentrations and optical properties of the $\mathrm{SO}_{4}{ }^{2-}-\mathrm{NH}_{4}{ }^{+}-\mathrm{H}_{2} \mathrm{O}$ mixture simulated by the aerosol composition model, our estimate increases to $-0.95 \mathrm{~W} / \mathrm{m}^{2}$ for the same sulfate burden. Including nitrate raises the forcing to $-1.14 \mathrm{~W} / \mathrm{m}^{2}$.

As mentioned in the Introduction, the sulfate forcing efficiencies implicit in published forcing estimates vary by more than a factor of 3 , largely because of uncertainties associated with sulfate optical properties. This study has sought to reduce these uncertainties by explicitly simulating the composition of the sulfate aerosol, thereby alleviating the need for some of the assumptions previously necessary regarding neutralization by ammonia and degree of water uptake. Figure 1 shows that our forcing estimate of -0.95 $\mathrm{W} / \mathrm{m}^{2}$ for sulfate, together with that of Taylor and Penner [1994] (not shown in Figure 1), is higher than all others cited here, partly because our anthropogenic sulfate burden is larger than others. Our sulfate forcing efficiency, $-290 \mathrm{~W} / \mathrm{g} \mathrm{SO}_{4}{ }^{2-}$, is higher than all others except those of Charlson et al. [1991] and Penner et al. [1998], but only 15\% higher than that of Kiehl et al. [2000]. Of the studies shown in Figure 1, our method for computing aerosol optical properties is most similar to those of Boucher and Anderson [1995], Penner et al. [1998], and Kiehl et al. [2000]. Except for Boucher and Anderson [1995], who use laboratory data, these authors predict water uptake using Köhler theory. Both the laboratory data and Köhler theory should yield results for water uptake similar to ours. All three studies compute optical properties using Mie scattering calculations on hydrated lognormal size distributions just as we do. Despite the similarities in methodology, there are surprising discrepancies in the resulting sulfate forcing efficiencies. Our value agrees with that of Kiehl et al. [2000] to within 15\%, but the forcing efficiency of Penner et al. [1998] is about 30\% higher. The fact that their model allows relative humidity to reach $100 \%$ over an entire grid cell before forming clouds is a likely explanation for their high forcing efficiency. The forcing efficiency from Boucher and Anderson [1995], -125 W/g $\mathrm{SO}_{4}{ }^{2-}$, is surprisingly low compared to the others. They cap their relative humidity at $95 \%$ while the others allow water uptake up to $99 \%$. Although this must explain some of the discrepancy, the sensitivity runs shown here and in other works make it clear that the difference in RH cutoff cannot explain the entire difference. A more systematic intercomparison of forcing efficiencies will be necessary to fully sort out the effects of various factors on forcing efficiency. These factors include treatment of water uptake, method of calculating optical properties, the radiation scheme used, and the distributions of relative humidity and cloud cover in the particular global model. Cloud amount is a potentially important difference between estimates from different models. For example, the simulated global mean cloud cover for our 3 -year period was $47 \%$. A comparison with satellite data from the International Satellite Cloud Climatology Project for the period beginning July 1983 and ending December 1990, during which the global mean cloud cover was estimated to be $63 \%$, suggests that this value is probably too low [Jakob, 1999]. If this is indeed the case, this factor alone could cause the forcing estimates and forcing efficiencies we report here to be high by as much as $15 \%$.

In summary, it is clear from this comparison that estimates of direct sulfate forcing, including those presented here, are subject to important uncertainties. First, there is the uncertainty regarding the anthropogenic sulfate burden, which varies by almost a factor of 2 amongst the estimates cited here. Second, given an anthropogenic sulfate burden, there is the uncertainty regarding its forcing efficiency, which varies by a factor of 3 . This uncertainty includes the effects of aerosol size distribution and chemical composition, biases in GCM cloud cover and relative humidity, and the difficulties associated with subgrid variations and correlations already discussed. Nevertheless, our results and others cited here suggest that, if sulfate at high relative humidities really does contribute significantly to direct forcing, this may have been underestimated in some previous work.

\section{Summary and Conclusions}

A model of aerosol composition that explicitly predicts the concentrations of nitrate, ammonium, and aerosol water as well as sulfate has been used to estimate direct radiative forcing by sulfate and nitrate. This is the first direct forcing estimate based on the equilibrium water content of a changing $\mathrm{SO}_{4}{ }^{2-}-\mathrm{NO}_{3}{ }^{-}-\mathrm{NH}_{4}{ }^{+}$mixture and the first estimate of nitrate forcing based on a global model of nitrate aerosol. It is intended that the explicit simulation of aerosol composition, especially water uptake, help to constrain aerosol optical properties, a key uncertainty in assessing direct forcing.

We estimate the present-day anthropogenic direct aerosol forcing to be $-0.95 \mathrm{~W} / \mathrm{m}^{2}$ for sulfate and $-0.19 \mathrm{~W} / \mathrm{m}^{2}$ for nitrate. Moreover, based on a plausible IPCC emissions scenario with especially strong increases in $\mathrm{NO}_{x}$ emissions, we predict that the nitrate forcing will increase to $-1.28 \mathrm{~W} / \mathrm{m}^{2}$ by the end of this century, even while sulfate forcing declines to $-0.85 \mathrm{~W} / \mathrm{m}^{2}$. This result shows that future estimates of aerosol forcing based solely on predicted sulfate concentrations may be highly misleading and that the potential for significant amounts of ammonium nitrate aerosol needs to be considered in estimates of future climate change.

A key finding of this study is that the calculated direct forcing is extremely sensitive to how the effect of water uptake on aerosol scattering behavior is taken into account. In particular, we find that the large amount of water taken up by the aerosol above $95 \%$ relative humidity increases the total forcing by about $60 \%$. This is important because a method commonly used in previous work for parameterizing the effect of water uptake on optical properties has been to assume a low RH scattering coefficient of $5 \mathrm{~m}^{2} / \mathrm{g} \mathrm{SO}_{4}{ }^{2-}$ and to correct for that at higher humidities with an empirical $f(\mathrm{RH})$ factor. In principle, there is nothing wrong with this approach, but in practice, lack of data about $f(\mathrm{RH})$ at high relative humidity has caused investigators to conservatively limit it to values that are unrealistically low. Even in studies where water uptake has been computed based on Köhler theory or laboratory data, investigators, ourselves included, have had to arbitrarily specify a cutoff RH beyond which they do not allow further water uptake. We have shown that the resulting estimate of aerosol forcing is very sensitive to the often unspecified choice of RH cutoff. Water uptake at high 
relative humidity therefore makes an important contribution to global forcing that has often been neglected without adequate discussion or even recognition of the consequences.

The results discussed here indicate several issues that require further attention. First, the large contribution to the forcing made by aerosol at high relative humidity emphasizes the need to understand potential correlations between aerosols, humidity, and clouds. Subgrid variability in these factors and correlations between them could be important for improving our estimate of direct aerosol forcing. These are effects that, by their nature, are not well represented in GCMs, the primary tool for global, long-term assessments of aerosol effects on climate. Little work has been done on this topic, but what has been done indicates that estimates of forcing based on GCM grid cell average humidity, such as the ones presented here, may be underestimates.

Second, further efforts should be made to evaluate GCM predictions of relative humidity. This will be difficult to achieve because there is a lack of data on the large spatial scales required to validate a global model with coarse resolution. Moreover, as long as one is interested primarily in cloud cover and precipitation rates, the details of the GCMpredicted relative humidity can be overlooked as long as they do not result in substantial errors in simulated clouds and rain. It is understandable, then, that GCM relative humidities have not been thoroughly and systematically evaluated. On the other hand, if one uses a GCM to estimate direct forcing of a hygroscopic aerosol, the details of the spatial and temporal distribution of grid-cell average relative humidity become important and require further attention.

Third, the potential for ammonium nitrate aerosol to contribute significantly to radiative forcing in the future highlights the need for a better understanding of tropospheric nitric acid and ammonia. Tropospheric photochemical models have generally had difficulty simulating nitric acid concentrations that match observations well, suggesting that important processes may be missing. This has not been a major problem as they have usually been used primarily to simulate ozone, but improving the treatment of nitric acid in tropospheric chemical models becomes more important in light of the potential future significance of nitrate aerosol forcing for climate change. Similarly, this study would have benefited from a more complete knowledge of ammonia emissions on a global scale. In particular, more data on past and future emissions and seasonal variability of emissions would help to improve and constrain model performance with regard to ammonia and ammonium nitrate aerosol.

Acknowledgments. This work has been supported by a graduate fellowship from the Fannie and John Hertz Foundation as well as by the National Aeronautics and Space Administration Earth Observing System Interdisciplinary Science program (NASA EOS-IDS). We also acknowledge Sigrun Karlsdottir and fellow researchers at the University of Oslo for providing nitric acid concentration fields from the Oslo CTM1.

\section{References}

Adams, P. J., J. H. Seinfeld, and D. M. Koch, Global concentrations of tropospheric sulfate, nitrate, and ammonium aerosol simulated in a general circulation model, J. Geophys. Res., 104, 13,791$13,823,1999$.

Andres, R. J., and A. D. Kasgnoc, A time-averaged inventory of subaerial volcanic sulfur emissions, J. Geophys. Res., I03, 25,251-25,261, 1998.
Ansari, A. S., and S. N. Pandis, Response of inorganic PM to precursor concentrations, Environ. Sci. Technol., 32, 2706-2714, 1998.

Berntsen, T. K., and I. S. A. Isaksen, A global three-dimensional chemical transport model for the troposphere: Model description and $\mathrm{CO}$ and $\mathrm{O}_{3}$ results, J. Geophys. Res., 102, 21,239-21,280, 1997.

Boucher, O., and T. L. Anderson, general circulation model assessment of the sensitivity of direct climate forcing by anthropogenic sulfate aerosols to aerosol size and chemistry, $J$. Geophys. Res., 100, 26,117-26,134, 1995.

Boucher, O., et al., Intercomparison of models representing direct shortwave radiative forcing by sulfate aerosols, J. Geophys. Res., I03, 16,979-16,998, 1998.

Bouwman, A. F., D. S. Lee, W. A. H. Asman, F. J. Dentener, K. W. Van Der Hoek, and J. G. J. Olivier, A global high-resolution emission inventory for ammonia, Global Biogeochem. Cycles, II, 561-587, 1997.

Charlson, R. J., D. S. Covert, and T. V. Larson, Observation of the effect of humidity on light scattering by aerosols, in Hygroscopic Aerosols, edited by L. Ruhnke and A. Deepak, pp. 35-44, A. Deepak, Hampton, Va., 1984.

Charlson, R. J., J. Langner, H. Rodhe, C. B. Leovy, and S. G. Warren, Perturbation of the Northern Hemisphere radiative balance by backscattering from anthropogenic sulfate aerosols, Tellus, Ser. A, 43, 152-163, 1991.

Chin, M., D. J. Jacob, G. M. Gardner, M. S. Foreman-Fowler, and P. A. Spiro, A global three-dimensional model of tropospheric sulfate, J. Geophys. Res., I0I, 18,667-18690, 1996.

Chuang, C. C., J. E. Penner, K. E. Taylor, A. S. Grossman, and J. J. Walton, An assessment of the radiative effects of anthropogenic sulfate, J. Geophys. Res., 102, 3761-3778, 1997.

Crutzen, P. J., and P. H. Zimmermann, The changing photochemistry of the troposphere, Tellus, 43A, 136-151, 1991.

Del Genio, A. D., and M.-S. Yao, Efficient cumulus parameterization for long-term climate studies: The GISS scheme, in The Representation of Cumulus Convection in Numerical Models, Monogr. 46, edited by K. A. Emanuel and D. J. Raymond, pp. 181-184, Am. Meteorol. Soc., Boston, Mass., 1993.

Del Genio, A. D., M.-S. Yao, W. Kovari, and K. K.-W. Lo, A prognostic cloud water parameterization for global climate models, J. Clim., 9, 270-304, 1996.

Dentener, F. J., and P. Crutzen, A three-dimensional model of the global ammonia cycle, J. Atmos. Chem., 19, 331-369, 1994.

Feichter, J., U. Lohmann, and I. Schult, The atmospheric sulfur cycle in ECHAM-4 and its impact on the shortwave radiation, Clim. Dyn., 13, 235-246, 1997.

Hansen, J., G. Russell, D. Rind, P. Stone, A. Lacis, S. Lebedeff, R. Ruedy, and L. Travis, Efficient three-dimensional global models for climate studies: Models I and II, Mon. Weather Rev., III, 609-662, 1983.

Haywood, J. M., V. Ramaswamy, and L. J. Donner, A limited-areamodel case study of the effects of sub-grid scale variations in relative humidity and cloud upon the direct radiative forcing of sulfate aerosol, Geophys. Res. Lett., 24, 143-146, 1997 a.

Haywood, J. M., D. L. Roberts, A. Slingo, J. M. Edwards, and K. P. Shine, general circulation model calculations of the direct radiative forcing by anthropogenic sulfate and fossil-fuel soot aerosol, J. Clim., 10, 1562-1577, 1997b.

Hjellbrekke, A.-G., and J. E. Hanssen, Data report 1996, 1, Annual summaries, EMEP/CCC Rep. 1/98, 85 pp., Norw. Inst. for Air Res., Lillestrom, 1998.

Horowitz, L. W., J. Liang, G. M. Gardner, and D. J. Jacob, Export of reactive nitrogen from North America during summertime: Sensitivity to hydrocarbon chemistry, J. Geophys. Res., I03, 13,451-13,476, 1998

Intergovernmental Panel on Climate Change (IPCC), Climate Change 1995, edited by J. T. Houghton et al., Cambridge Univ. Press, New York, 1996.

Jaffe, D., T. K. Berntsen, and I. S. A. Isaksen, A global threedimensional chemical transport model, 2, Nitrogen oxides and nonmethane hydrocarbon results, J. Geophys. Res., 102, 21,28121,296, 1997.

Jakob, C., Cloud cover in the ECMWF reanalysis, J. Clim., 12, 947$959,1999$. 
Kiehl, J. T., and B. P. Briegleb, The relative roles of sulfate aerosols and greenhouse gases in climate forcing, Science, 260, 311-314, 1993.

Kiehl, J. T., T. L. Schneider, P. J. Rasch, M. C. Barth, and J. Wong, Radiative forcing due to sulfate aerosols from simulations with the National Center for Atmospheric Research Community Climate Model, Version 3, J. Geophys. Res., 105, 1441-1457, 2000.

Koch, D. M., D. Jacob, I. Tegen, D. Rind, and M. Chin, Tropospheric sulfur simulation and sulfate direct radiative forcing in the GISS GCM, J. Geophys. Res., 104, 23,799-23,822, 1999.

Lacis, A. A., and J. E. Hansen, Parameterization for the absorption of solar radiation in the Earth's atmosphere, J. Atmos. Sci., 31, 118133,1974

Lacis, A. A., and M. I. Mishchenko, Climate forcing, climate sensitivity, and climate response: A radiative modeling perspective on atmospheric aerosols, in Aerosol Forcing of Climate, edited by R. J. Charlson and J. Heintzenberg, pp. 11-42, John Wiley, New York, 1995.

Lacis, A. A., and V. Oinas, A description of the correlated $k$ distribution method for modeling non-gray gaseous absorption, thermal emission, and multiple scattering in vertically inhomogeneous atmospheres, J. Geophys. Res., 96, 9027-9064, 1991.

McNaughton, D. J., and R. J. Vet, Eulerian model evaluation field study (EMEFS): A summary of surface network measurements and data quality, Atmos. Environ., 30, 227-238, 1996.

Meng, Z., and J. H. Seinfeld, Time scales to achieve atmospheric gas-aerosol equilibrium for volatile species, Atmos. Environ., 30, 2889-2900, 1996

Mickley, L. J., P. Murti, D. Jacob, J. Logan, and D. Rind, Radiative forcing from tropospheric ozone calculated with a unified chemistry-climate model, J. Geophys. Res., I04, 30,153-30,172, 1999.

Nemesure, S., R. Wagener, and S. E. Schwartz, Direct shortwave forcing of climate by the anthropogenic sulfate aerosol: Sensitivity to particle size, composition, and relative humidity, $J$. Geophys. Res., 100, 26,105-26,116, 1995.

Nenes, A., C. Pilinis, and S. N. Pandis, ISORROPIA: A new thermodynamic equilibrium model for multiphase multicomponent inorganic aerosols, Aquat. Geochem., 4, 123$152,1998$.

Penner, J. E., C. C. Chuang, and K. Grant, Climate forcing by carbonaceous and sulfate aerosols, Clim. Dyn., 14, 839-851, 1998.

Pilinis, C., S. N. Pandis, and J. H. Seinfeld, Sensitivity of direct climate forcing by atmospheric aerosols to aerosol size and composition, J. Geophys. Res., 100, 18,739-18,754, 1995.

Rasch, P. J., M. C. Barth, J. T. Kiehl, S. E. Schwartz, and C. M. Benkovitz, A description of the global sulfur cycle and its controlling processes in the National Center for Atmospheric Research Community Climate Model, Version 3, J. Geophys. Res., 105, 1367-1385, 2000.

Rind, D., and J. Lerner, The use of on-line tracers as a diagnostic tool in general circulation model development, 1, Horizontal and vertical transport in the troposphere, J. Geophys. Res., 101, 12,667-12,683, 1996.

Stelson, A. W., Urban aerosol refractive index prediction by partial molar refraction approach, Environ. Sci. Technol., 24, 16761679,1990
Tang, I. N., Chemical and size effects of hygroscopic aerosols on light scattering coefficients, J. Geophys. Res., 101, 19,24519,250, 1996.

Tang, I. N., Thermodynamic and optical properties of mixed-salt aerosols of atmospheric importance, J. Geophys. Res., 102, 1883$1893,1997$.

Tang, I. N., and H. R. Munkelwitz, Water activities, densities, and refractive indices of aqueous sulfates and sodium nitrate droplets of atmospheric importance, J. Geophys. Res., 99, 18,801-18,808, 1994.

Taylor, K. E., and J. E. Penner, Response of the climate system to atmospheric aerosols and greenhouse gases, Nature, 369, 734737, 1994.

ten Brink, H. M., J. P. Veefkind, A. Waijers-Ijpelaan, and J. C. van der Hage, Aerosol light-scattering in The Netherlands, Atmos. Environ., 30, 4251-4261, 1996.

ten Brink, H. M., C. Kruisz, G. P. A. Kos, and A. Berner, Composition/size of the light-scattering aerosol in The Netherlands, Atmos. Environ., 31, 3955-3962, 1997.

Van Dorland, R., F. J. Dentener, and J. Lelieveld, Radiative forcing due to tropospheric ozone and sulfate aerosols, J. Geophys. Res., 102, 28,079-28,100, 1997.

Wang, Y., D. J. Jacob, and J. A. Logan, Global simulation of tropospheric $\mathrm{O}_{3}-\mathrm{NO}_{x}$-hydrocarbon chemistry, 1, Model formulation, J. Geophys. Res., 103, 10,713-10,726, 1998 a.

Wang, Y., J. A. Logan, and D. J. Jacob, Global simulation of tropospheric $\mathrm{O}_{3}-\mathrm{NO}_{x}$-hydrocarbon chemistry, 2, Model evaluation and global ozone budget, J. Geophys. Res., 103, 10,727-10,756, 1998b.

Wang, Y., D. J. Jacob, and J. A. Logan, Global simulation of tropospheric $\mathrm{O}_{3}-\mathrm{NO}_{x}$-hydrocarbon chemistry, 3, Origin of tropospheric ozone and effects of nonmethane hydrocarbons, $J$. Geophys. Res., 103, 10,757-10,768, 1998c.

Wesely, M. L., and B. B. Hicks, Some factors that affect the deposition rates of sulfur dioxide and similar gases on vegetation, J. Air Pollut. Control Assoc., 27, 1110-1116, 1977.

West, J. J., C. Pilinis, A. Nenes, and S. N. Pandis, Marginal direct climate forcing by atmospheric aerosols, Atmos. Environ., 32, 2531-2542, 1998

West, J. J., A. S. Ansari, and S. N. Pandis, Marginal PM 2.5: Nonlinear aerosol mass response to sulfate reductions in the eastern United States, J. Air Waste Manage. Assoc., 49, 1415$1424,1999$.

P. J. Adams and J. H. Seinfeld, Department of Chemical Engineering, California Institute of Technology, Mail Code 104-44, Pasadena, CA 91125. (petera@its.caltech.edu; seinfeld@caltech.edu)

D. Jacob and L. Mickley, Division of Engineering and Applied Sciences, Harvard University, Pierce Hall, 29 Oxford St., Cambridge, MA 02138.

D. Kock, NASA Goddard Institute for Space Studies, 2880 Broadway, New York, NY 10025

(Received February 17, 2000; revised August 15, 2000; accepted August 25, 2000.) 